\title{
A major recessive gene associated with anthracnose resistance to Colletotrichum capsici in chili pepper (Capsicum annuum L.)
}

\author{
Sang Hoon Kim, Jae Bok Yoon*, Jae Wahng Do and Hyo Guen Park \\ Research and Development Unit, Pepper and Breeding Institute, Business Incubator, College of Agriculture and Life Sciences, Seoul \\ National University, Suwon 441-853, Korea
}

\begin{abstract}
Pepper (Capsicum annuиm L.) anthracnose, caused by Colletotrichum spp., is an important disease in many Asian countries. Recently, it was found that a local Korean variety, C. annuum 'Daepoong-cho', had resistance to $C$. capsici. Inheritance of resistance to $C$. capsici was analyzed in segregating populations derived from a cross of 'Yeoju' $\times$ 'Daepoong-cho'. An allelism test was carried out in $\mathrm{F}_{1}$ and $\mathrm{F}_{2}$ progenies derived from the cross of 'Daepoong-cho' $\times$ 'AR'. 'AR' is an anthracnose-resistant breeding line derived from C. chinense Jacq. 'PBC 932'. Detached mature green fruits were inoculated using the microinjection method. Disease response was evaluated using disease incidence, overall lesion diameter, and true lesion diameter at 7 days after inoculation. The segregation ratios of resistance and susceptibility to C. capsici in $\mathrm{F}_{2}$ and $\mathrm{BC}_{\mathrm{R}}$ populations derived from the cross of 'Yeoju' $\times$ 'Daepoong-cho' were fitted to the $1: 3$ and $1: 1$ Mendelian model, respectively. This indicates that the resistance of 'Daepoong-cho' to C. capsici is controlled by a single recessive gene. The results of the allelism test indicated that the two resistant lines, 'Daepoong-cho' and 'AR', possessed the same resistance gene to $C$. capsici, even though the resistance genes of these two lines originated from different Capsicum species, C. annuum and C. chinense.
\end{abstract}

Key Words: Capsicum annuum, Capsicum chinense, Colletotrichum capsici, allelism test, anthracnose, inheritance.

\section{Introduction}

Pepper (Capsicum annuum L.) anthracnose caused by several Colletotrichum spp. results in serious yield loss and quality deterioration in many Asian counties, including Thailand and Indonesia. In these countries, the causal pathogens are C. gloeosporioides, C. capsici, and C. acutatum. The primarily causal pathogens in Thailand and Indonesia are C. gloeosporioides and C. capsici (Lin et al. 2002, Voorrips et al. 2004). C. gloeosporioides attacks pepper fruits at both the green and red stages, while $C$. capsici mainly attacks pepper fruits at the red stage (Park et al. 1990a). Many fungicides are used to control the disease in developing countries, but these not only reduce producer income but also cause consumer antipathy. The most economic and environmentally friendly method is to develop resistant varieties; however, there is currently no known resistant cultivar.

Several sources of resistance to $C$. capsici have been reported (Cheema et al. 1984, Lin et al. 2002, Pakdeevaraporn et al. 2005, Park et al. 1990b, Voorrips et al. 2004) and, using these resources, researchers have studied the inheritance of anthracnose resistance (Lin et al. 2002, Pakdeevaraporn et al. 2005, Park et al. 1990b, Voorrips et al. 2004). How-

Communicated by J.M. Boman

Received December 10, 2007. Accepted February 11, 2008.

*Corresponding author (e-mail: yoonjb2@snu.ac.kr) ever, inheritance patterns vary depending on the source of resistance and the Colletotrichum isolate. For instance, resistance to $C$. capsici ' $158 \mathrm{ci}$ ' in the $C$. annuum breeding line ' $83-168$ ' is inherited by a single dominant gene (Lin et al. 2002), and resistance to C. dematium, a synonym for $C$. capsici, in $C$. annuum 'Chungryong' is inherited by partial dominance (Park et al. 1990b). In contrast, some reports have found that resistance to $C$. capsici was inherited recessively. For example, resistance to $C$. capsici was inherited recessively, with epistatic effects (Cheema et al. 1984), and resistance to $C$. capsici ' $158 \mathrm{ci}$ ' in $C$. chinense Jacq. 'PBC 932' was inherited through a single recessive gene (Pakdeevaraporn et al. 2005).

Recently, a source of resistance to $C$. capsici was identified in C. annuum 'Daepoong-cho', a local Korean variety (unpublished data). Here we analyzed the inheritance of resistance to C. capsici in C. annuum 'Daepoong-cho', and examined allelism between 'Daepoong-cho' and 'AR', which has resistance derived from $C$. chinense Jacq. 'PBC 932'. The results may provide useful information for breeding pepper anthracnose resistance.

\section{Materials and Methods}

\section{Plant materials}

Two Korean open-pollinated varieties, 'Daepoongcho' (resistant) and 'Yeoju' (susceptible), developed by our 
company (PBI) were used for an inheritance study of anthracnose resistance to Colletotrichum capsici. $\mathrm{F}_{1}$ plants were obtained from the cross 'Yeoju' $\times$ 'Daepoong-cho' and $\mathrm{F}_{2}$ seed was also produced. Backcross populations, $\mathrm{BC}_{\mathrm{R}}$ and $\mathrm{BC}_{\mathrm{S}}$, were produced by backcrossing $\mathrm{F}_{1}$ plants to 'Daepoong-cho' and 'Yeoju', respectively.

For the allelism test, 'Daepoong-cho' and 'AR' were used as parents. 'AR' is a resistant line selected from the $\mathrm{BC}_{3} \mathrm{~F}_{6}$ generation derived from $C$. chinense Jacq. 'PBC 932', which was introduced by the Asian Vegetable Research and Development Center (AVRDC) in 2003. $F_{1}$ plants were obtained from the cross 'Daepoong-cho' $\times$ 'AR' and $\mathrm{F}_{2}$ seed was also produced.

In the cross 'Yeoju' $\times$ 'Daepoong-cho' for the inheritance study, populations consisting of resistant parent (six plants), susceptible parents (six plants), $\mathrm{F}_{1}$ (six plants), $\mathrm{BC}_{\mathrm{R}}$ (38 plants), $\mathrm{BC}_{\mathrm{S}}$ (20 plants), and $\mathrm{F}_{2}$ (91 plants) were grown in a greenhouse at Seoul National University, Suwon, Korea, from November 2005 to May 2006. In the cross 'Daepoongcho' $\times$ 'AR' for the allelism test, the populations consisted of resistant parents (six plants), susceptible parents (six plants), $\mathrm{F}_{1}$ (six plants), and $\mathrm{F}_{2}$ (105 plants). All plants were grown in a greenhouse at the same location from January to October 2006. Plants with virus disease symptoms were discarded.

\section{Fungal isolate}

C. capsici 'ThSCc-1' was obtained from the Seminis Thailand Co., as described previously (Park 2005). The isolate was purified by the single spore isolation method with slight modification (Ho and Ko 1997), maintained on potato dextrose agar medium (Sigma Chemical Co.) at $25^{\circ} \mathrm{C}$ under $16 \mathrm{~h}$ fluorescent light $/ 8 \mathrm{~h}$ dark in a incubation room, and incubated for 7 days on plates flooded with distilled water. Conidia were collected by scraping the culture surface. Inoculum density was adjusted to $5 \times 10^{5}$ conidia/ml using a hemacytometer.

\section{Inoculation}

Inoculation was conducted by the microinjection method developed by AVRDC (1999). Three to five fruits of the mature-green stage were harvested from individual plants. The detached fruits were washed in distilled water. Inoculation was conducted at a depth of $0.7 \mathrm{~mm}$ using a microinjector (Hamilton PB600-1, Repeating Dispenser). Each fruit was injected with $2 \mu \mathrm{l}$ of prepared conidial suspension, and two or three sites were inoculated, depending on the fruit size. Inoculation was conducted using three replications.
The inoculated fruits were placed on moistened paper towels with $100 \mathrm{ml}$ distilled water in acrylic boxes.

The boxes with inoculated fruits were sealed tightly in wrapping material to maintain more than $95 \%$ relative humidity, and incubated for $48 \mathrm{~h}$ under the same conditions as used for fungus maintenance. Finally, the wrapping was removed and inoculated fruits were incubated for another 5 days under the same conditions.

\section{Disease evaluation}

Disease evaluation was conducted using the disease incidence (percentage of infected sites per total inoculated sites), overall lesion diameter (averaged over all inoculation points, including those that did not develop lesions), and true lesion diameter (averaged over all lesions that actually developed) method at 7 days after inoculation (DAI), as described previously (Voorrips et al. 2004). A chi-squared goodness-of-fit test was used for statistical analysis.

\section{Results}

\section{Inheritance of resistance to Colletotrichum capsici in 'Daepoong-cho'}

Anthracnose symptoms on susceptible parent, 'Yeoju', started to develop at $2 \mathrm{DAI}$, and there was no further change in disease incidence after 7 DAI (data not shown). Hence, the time of disease evaluation for inheritance analysis was determined at 7 DAI. The values of disease incidence, overall lesion diameter, and true lesion diameter in parents and $F_{1}$ plants are shown in Table 1. Resistant and susceptible parents showed distinct differences in disease incidence and overall lesion diameter (Table 1); however, there was no significant difference between the two parents in true lesion diameter (Table 1). Disease reactions of $F_{1}$ plants in disease incidence and overall lesion diameter were very similar to their susceptible parents, with average values of $67.9 \%$ and $19.0 \mathrm{~mm}$, respectively. These data indicate that the resistant parent, 'Daepoong-cho', has a recessive gene conferring resistance to anthracnose.

Distribution of disease incidence in the $F_{2}$ population was skewed toward the susceptible parent (Fig. 1), and the distribution of overall lesion diameter in the $F_{2}$ population showed a similar trend (Fig. 1). To determine the criteria of resistance and susceptibility, we scored the disease reactions of segregating populations using disease indices, disease incidence and overall lesion diameter. As a result, the distribution of disease incidence and overall lesion diameter in $\mathrm{F}_{2}$

Table 1. Disease incidence, overall lesion diameter and true lesion diameter for 'Daepoong-cho', 'Yeoju', and their $\mathrm{F}_{1}$ progenies 7 days after inoculation with C. capsici 'ThSCc-1'

\begin{tabular}{lccc}
\hline \hline Population & Disease incidence $(\%)$ & Overall lesion diameter $(\mathrm{mm})$ & True lesion diameter $(\mathrm{mm})$ \\
\hline Daepoong-cho & $12.5 \pm 2.0^{a}$ & $3.1 \pm 0.1$ & $25.0 \pm 4.7$ \\
Yeoju & $90.5 \pm 1.6$ & $24.4 \pm 0.4$ & $27.0 \pm 0.1$ \\
F $_{1}$ (Yeoju $\times$ Daepoong-cho) & $67.9 \pm 21.9$ & $19.0 \pm 6.2$ & $27.9 \pm 0.1$ \\
\hline
\end{tabular}

\footnotetext{
${ }^{a}$ Mean \pm standard deviation
} 


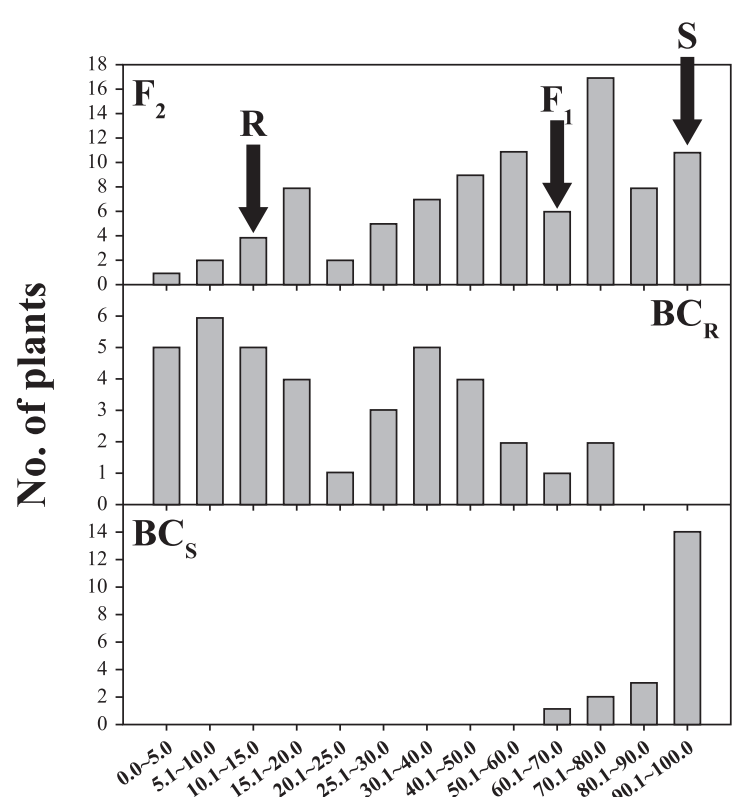

Disease incidence (\%)

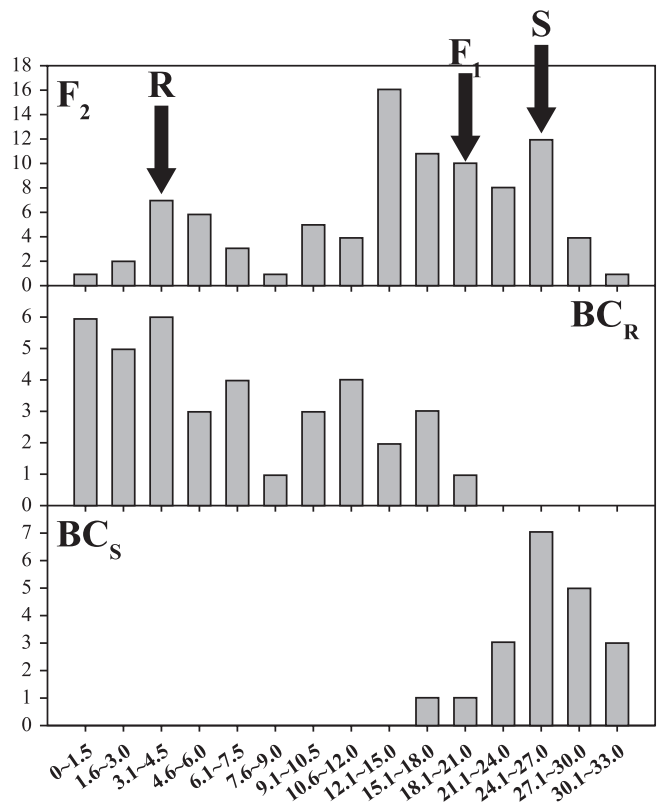

Overall lesion diameter $(\mathrm{mm})$

Fig. 1. Distribution of disease incidence and overall lesion diameter in $F_{2}, B C_{R}$, and $B_{S}$ populations derived from the cross 'Yeoju' $\times$ 'Daepoong-cho'.

Table 2. Segregation ratios of resistance and susceptibility scored by disease incidence and overall lesion diameter in segregating populations derived from the cross 'Yeoju' $\times$ 'Daepoong-cho'

\begin{tabular}{|c|c|c|c|c|c|}
\hline \multirow{2}{*}{ Population } & \multirow{2}{*}{$\begin{array}{c}\text { Expected ratio } \\
(\mathrm{R}: \mathrm{S})\end{array}$} & \multicolumn{2}{|c|}{ Observed frequency } & \multirow{2}{*}{$\chi^{2}$} & \multirow{2}{*}{ Probability } \\
\hline & & $\mathrm{R}$ & $\mathrm{S}$ & & \\
\hline \multicolumn{6}{|l|}{ Disease incidence $^{a}$} \\
\hline Daepoong-cho & - & 6 & 0 & - & - \\
\hline Yeoju & - & 0 & 6 & - & - \\
\hline $\mathrm{F}_{1}($ Yeoju $\times$ Daepoong-cho $)$ & - & 0 & 6 & - & - \\
\hline $\mathrm{F}_{2}$ & $1: 3$ & 17 & 74 & 1.94 & 0.164 \\
\hline $\mathrm{BC}_{\mathrm{R}}$ & $1: 1$ & 21 & 17 & 0.421 & 0.516 \\
\hline $\mathrm{BC}_{\mathrm{S}}$ & $0: 1$ & 0 & 20 & - & - \\
\hline \multicolumn{6}{|l|}{ Overall lesion diameter ${ }^{b}$} \\
\hline Daepoong-cho & - & 6 & 0 & - & - \\
\hline Yeoju & - & 0 & 6 & - & - \\
\hline$F_{1}($ Yeoju $\times$ Daepoong-cho $)$ & - & 0 & 6 & - & - \\
\hline $\mathrm{F}_{2}$ & $1: 3$ & 20 & 71 & 0.443 & 0.506 \\
\hline $\mathrm{BC}_{\mathrm{R}}$ & $1: 1$ & 25 & 13 & 3.79 & 0.052 \\
\hline $\mathrm{BC}_{\mathrm{S}}$ & $0: 1$ & 0 & 20 & - & - \\
\hline
\end{tabular}

${ }^{a}$ Less than $25.0 \%$ disease incidence was evaluated as resistance.

${ }^{b}$ Less than $9.0 \mathrm{~mm}$ overall lesion diameter was evaluated as resistance.

and $\mathrm{BC}_{\mathrm{R}}$ populations was divided using the criteria of $25.0 \%$ and $9.0 \mathrm{~mm}$, respectively (Fig. 1). Based on the criteria of resistance and susceptibility, less than $25.0 \%$ disease incidence or less than $9.0 \mathrm{~mm}$ overall lesion diameter were classified as resistance.

The segregation of resistance and susceptibility scored by disease incidence in the $F_{2}$ population was 17 to 74 (Table 2). The chi-squared and probability values in the $F_{2}$ population were 1.94 and 0.164 , respectively, which fitted one recessive gene model (Table 2). Segregation ratios in $B C_{R}$ and $B C_{S}$ populations were $21: 17$ and $0: 20$, respective- ly, which fitted the expected segregation ratios, $1: 1$ and $0: 1$, respectively (Table 2 ). Segregation of resistance and susceptibility scored by overall lesion diameter in the $F_{2}$ population was 20 to 71 (Table 2). Segregation ratios in $B_{R}$ and $\mathrm{BC}_{\mathrm{S}}$ populations were $25: 13$ and $0: 20$, respectively (Table 2). This result was also fitted to the one recessive gene model.

\section{Allelism test between 'Daepoong-cho' and 'AR'}

Anthracnose resistance to $C$. capsici is inherited through a single recessive gene in $C$. chinense Jacq. 'PBC 
Table 3. Disease incidence, overall lesion diameter and true lesion diameter for 'Daepoong-cho', 'AR', and their $\mathrm{F}_{1}$ progenies 7 days after inoculation with C. capsici 'ThSCc-1'

\begin{tabular}{lccc}
\hline \hline Population & Disease incidence $(\%)$ & Overall lesion diameter $(\mathrm{mm})$ & True lesion diameter $(\mathrm{mm})$ \\
\hline Daepoong-cho & $12.3 \pm 5.9^{a}$ & $2.8 \pm 1.5$ & $22.9 \pm 4.1$ \\
AR & $0.0 \pm 0.0$ & $0.0 \pm 0.0$ & NA $^{b}$ \\
$\mathrm{~F}_{1}$ (Daepoong-cho $\left.\times \mathrm{AR}\right)$ & $2.8 \pm 3.4$ & $0.6 \pm 0.8$ & $24.7 \pm 5.7$ \\
\hline
\end{tabular}

${ }^{a}$ Mean \pm standard deviation

${ }^{b} \mathrm{NA}$ : not analyzed, this accession showed no symptoms.

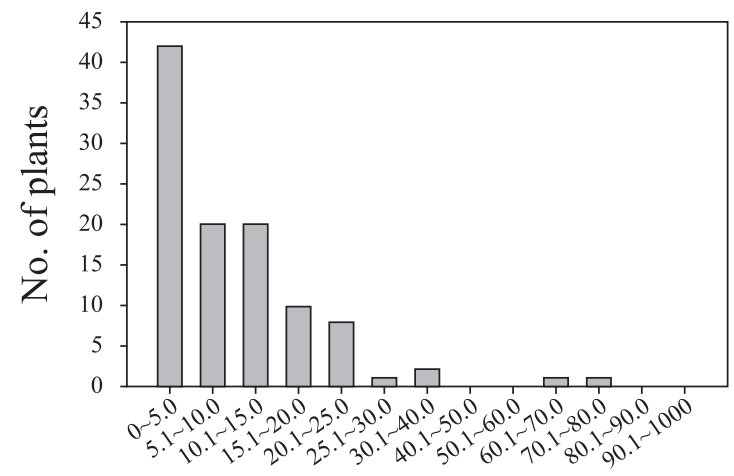

Disease incidence (\%)

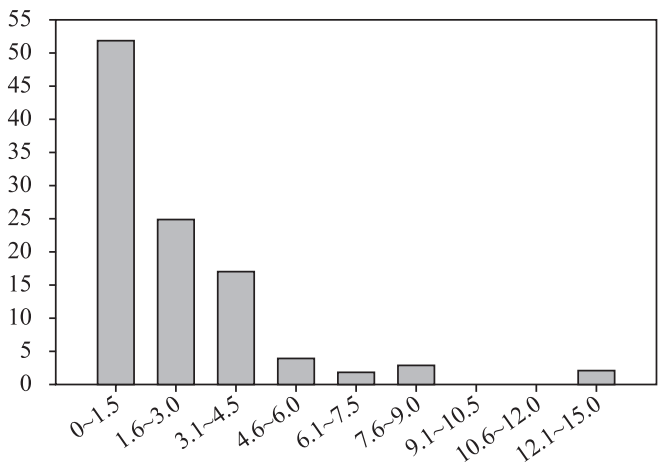

Overall lesion diameter $(\mathrm{mm})$

Fig. 2. Distribution of disease incidence and overall lesion diameter in the $F_{2}$ population derived from the cross 'Daepoong-cho' $\times$ 'AR'.

932' (Pakdeevaraporn et al. 2005), therefore, to test whether the resistance gene of 'Daepoong-cho' to $C$. capsici was the same as that of 'AR', with resistance derived from 'PBC 932', an allelism test was carried out in the cross 'Daepoong-cho' $\times$ 'AR'.

The values of disease incidence, overall lesion diameter, and true lesion diameter in parents and $F_{1}$ plants are shown in Table 3. Both parents showed little difference in disease incidence and overall lesion diameter, but based on the criterion of a $25.0 \%$ disease incidence or $9.0 \mathrm{~mm}$ overall lesion diameter, they belong to the resistant type (Table 3 ). Few disease symptoms developed in 'Daepoong-cho', but complete resistance was found in 'AR', as previously reported (Pakdeevaraporn et al. 2005). $\mathrm{F}_{1}$ plants showed a resistance response, and disease incidence and overall lesion diameter in $F_{1}$ plants were skewed toward 'AR' (Table 3); therefore, it appears that 'Daepoong-cho' and 'AR' have the same resistance gene to $C$. capsici. Distributions of disease incidence and overall lesion diameter in the $F_{2}$ population are shown in Fig. 2.

Segregation of resistance and susceptibility to disease incidence in the $F_{2}$ population was 100 to 5 (Table 4 ). The five susceptible plants were segregated as follows: three plants had $25.1-40.0 \%$ disease incidence, and two plants had $60.1-80.0 \%$ disease incidence (Fig. 2). Segregation of resistance and susceptibility for overall lesion diameter in the $\mathrm{F}_{2}$ population was 103 to 2 (Table 4). The two susceptible plants had 12.1-15.0 mm overall lesion diameter (Fig. 2). It was thus reconfirmed in the $\mathrm{F}_{2}$ population that 'Daepoongcho' and 'AR' had the same resistance gene. These results also suggest that $C$. annuum 'Daepoong-cho' and $C$. chinense
Jacq. 'PBC 932' have the same resistance gene, since resistance in 'AR' was derived from 'PBC 932'.

\section{Discussion}

\section{Inheritance of resistance to Colletotrichum capsici in 'Daepoong-cho'}

The distribution of segregating populations and results of chi-squared tests in the cross 'Yeoju' $\times$ 'Daepoong-cho' indicate that the resistance of 'Daepoong-cho' to $C$. capsici is controlled by a single recessive gene; however, the continuous distribution of segregating populations suggests that minor genes could exist and affect resistance. There were no significant differences in the true lesion diameter of parents and their $F_{1}$ progenies. This suggests that the resistance mechanism to $C$. capsici could be related to the initiation stage of pathogen invasion and is unable to repress disease symptom expansion; however, Pakdeevaraporn et al. (2005) suggested that the resistance of $C$. chinense Jacq. 'PBC 932' to $C$. capsici could be due to the repression of disease symptom expansion; therefore, it was necessary to carry out an allelism test between 'Daepoong-cho' and 'PBC 932'.

\section{Allelism test between 'Daepoong-cho' and 'AR'}

To confirm whether the resistance gene of 'Daepoongcho' to $C$. capsici was the same gene as that in 'AR', an allelism test was carried out in the cross 'Daepoong-cho' $\times$ 'AR'. The responses of $F_{1}$ and $F_{2}$ generations suggest that 'Daepoong-cho' and 'AR' had the same resistance gene to C. capsici, even though resistant genes were derived from other Capsicum spp., C. annuum and $C$. chinense, respectively. 
Table 4. Segregation ratios of resistance and susceptibility scored by disease incidence and overall lesion diameter in segregating populations derived from the cross 'Daepoong-cho' $\times$ 'AR'

\begin{tabular}{|c|c|c|c|c|c|}
\hline \multirow{2}{*}{ Population } & \multirow{2}{*}{$\begin{array}{c}\text { Expected ratio } \\
(\mathrm{R}: \mathrm{S})\end{array}$} & \multicolumn{2}{|c|}{ Observed frequency } & \multirow{2}{*}{$\chi^{2}$} & \multirow{2}{*}{ Probability } \\
\hline & & $\mathrm{R}$ & $\mathrm{S}$ & & \\
\hline \multicolumn{6}{|l|}{ Disease incidence $^{a}$} \\
\hline Daepoong-cho & - & 6 & 0 & - & - \\
\hline $\mathrm{AR}$ & - & 6 & 0 & - & - \\
\hline$F_{1}($ Daepoong-cho $\times A R)$ & - & 6 & 0 & - & - \\
\hline $\mathrm{F}_{2}$ & $1: 0$ & 100 & 5 & - & - \\
\hline \multicolumn{6}{|l|}{ Overall lesion diameter ${ }^{b}$} \\
\hline Daepoong-cho & - & 6 & 0 & - & - \\
\hline AR & - & 6 & 0 & - & - \\
\hline$F_{1}($ Daepoong-cho $\times A R)$ & - & 6 & 0 & - & - \\
\hline $\mathrm{F}_{2}$ & $1: 0$ & 103 & 2 & - & - \\
\hline
\end{tabular}

${ }^{a}$ Less than $25.0 \%$ disease incidence was evaluated as resistance.

${ }^{b}$ Less than $9.0 \mathrm{~mm}$ overall lesion diameter was evaluated as resistance.

This indicates that the resistance gene in $C$. annuum 'Daepoong-cho' could be an ortholog of the anthracnose resistance gene in C. chinense Jacq. 'PBC 932'; however, the resistance level between the two resistant lines differed. Few disease symptoms developed in 'Daepoong-cho', but 'AR' had complete resistance, similar to immune resistance, which has been reported previously (Pakdeevaraporn et al. 2005). This suggests that 'AR' could have additional minor genes other than those of 'Daepoong-cho'. Also, the response of $F_{1}$ and $F_{2}$ plants suggests that additional minor genes were inherited dominantly. Five plants were classified as susceptible to disease incidence; among them, three plants were classified as resistant in terms of overall lesion diameter; the other two plants, classified as susceptible in both disease incidence and overall lesion diameter, may be the result of pollen contamination.

\section{Acknowledgments}

This work was supported by a grant (code number 20050301034408) from the BioGreen 21 Program, Rural Development Administration, Republic of Korea.

\section{Literature Cited}

AVRDC (1999) Off-season tomato, pepper and eggplant. In: AVRDC
Report 1998, Tainan, Taiwan. pp.20-30.

Cheema, D.S., D.P.Singh, R.D. Rawal and A.A.Deshpande (1984) Inheritance of resistance to anthracnose disease in chillies. Capsicum Eggplant Newsl. 3: 44.

Ho, W.C. and W.H.Ko (1997) A simple method for obtaining singlespore isolates of fungi. Bot. Bull. Acad. Sin. 38: 41-44.

Lin, Q., C.Kanchana-udomkarn, T.Jaunet and O.Mongkolporn (2002) Genetic analysis of resistance to pepper anthracnose caused by Colletotrichum capsici. Thai J. Agric. Sci. 35: 259-264.

Pakdeevaraporn, P., S. Wasee, P.W.J. Taylor and O.Mongkolporn (2005) Inheritance of resistance to anthracnose caused by Colletotrichum capsici in Capsicum. Plant Breeding 124: 206208.

Park, H.K., B.S.Kim and W.S.Lee (1990a) Inheritance of resistance to anthracnose (Colletotrichum spp.) in pepper (Capsicum annuит L.) I. Genetic analysis of anthracnose resistance by diallel crosses. J. Kor. Soc. Hort. Sci. 31: 91-105.

Park, H.K., B.S.Kim and W.S.Lee (1990b) Inheritance of resistance to anthracnose (Colletotrichum spp.) in pepper (Capsicum annuum L.) II. Genetic analysis of resistance to Colletotrichum dematium. J. Kor. Soc. Hort. Sci. 31: 207-212.

Park, S.K. (2005) Differential interaction between pepper genotypes and Colletotrichum isolates causing anthracnose. MS Thesis, Seoul Natl. Univ., Seoul, Korea.

Voorrips, R.E., R.Finkers, L. Sanjaya and R.Groenwold (2004) QTL mapping of anthracnose (Colletotrichum spp.) resistance in a cross between Capsicum annum and C. chinense. Theor. Appl. Genet. 109: 1275-1282. 